\title{
Interleukin-18 polymorphism as a diagnostic tumor marker for hepatocellular carcinoma in patients with hepatitis C- related cirrhosis
}

Ayman Abdelghaffar Eldesoky ${ }^{1}$, Nancy Abdel Fattah Ahmed ${ }^{1 *}$, Hosam Eldeen Zaghloul ${ }^{2}$ and Amr Ahmed Abdel Aziz ${ }^{3}$

\begin{abstract}
Background: Egypt has the highest hepatitis C virus prevalence worldwide where about 24\% of the people are estimated to carry HCV and more than 50\% of blood donors have anti-HCV in some towns. The burden of hepatocellular carcinoma has been increasing in Egypt with a doubling in the incidence rate in the past 10 years. Thus, the aim of the present study was to analyze the interleukin-18 single nucleotide polymorphisms (SNPs) as a diagnostic tumor marker for hepatocellular carcinoma in patients with hepatitis C-related cirrhosis.

Results: This study included 33 hepatocellular carcinoma (HCC) complicating HCV-related cirrhosis patients, 37 cirrhotic patients without HCC (cirrhosis group), and 20 healthy individuals who were included as a control for 9 months of follow-up. SNPs of the IL-18 gene were genotyped by polymerase chain reaction. There was a statistically significant difference in the GG genotype in the HCC group in comparison with the control group $(P=$ 0.04). There was a statistically significant difference in the $G$ allele in the cirrhosis and HCC groups in comparison with the control group ( $p 1<0.001$ and $p 2=0.03$, respectively). Patients with GC genotype have a risk for developing HCC by 6.33-folds more than those with GG genotype while patients with GC genotype have a risk for developing cirrhosis by 5.43-folds more than those with GG genotype, and cirrhotic patients with CC and GC genotype had a risk for developing HCC by 1.17-folds more than those with GG genotype.

Conclusion: Our findings revealed that the analysis of IL-18 single nucleotide gene polymorphism could be a valuable marker for the prediction of progress towards cirrhosis in chronic HCV patients and also to subsequent development of HCC in HCV cirrhotic patients proved by the results of both GG genotype and its G allele; also, cirrhotic patients with CC and GC genotype have a risk for developing HCC by 1.17-folds more than those with GG genotype.
\end{abstract}

Keywords: HCV, HCC, SNPs

\footnotetext{
* Correspondence: ziad.emad90@yahoo.com

Study design:

The present study was cross sectional in nature and our patients were selected from the hepatology outpatient clinics in Mansoura Specialized Medical Hospital.

'Internal Medicine Department Hepatology \& Gastroenterology Unit, Mansoura Specialized Medical Hospital, Mansoura University Faculty of Medicine, Mansoura, Egypt

Full list of author information is available at the end of the article
}

\section{Springer Open}

(c) The Author(s). 2020 Open Access This article is licensed under a Creative Commons Attribution 4.0 International License, which permits use, sharing, adaptation, distribution and reproduction in any medium or format, as long as you give appropriate credit to the original author(s) and the source, provide a link to the Creative Commons licence, and indicate if changes were made. The images or other third party material in this article are included in the article's Creative Commons licence, unless indicated otherwise in a credit line to the material. If material is not included in the article's Creative Commons licence and your intended use is not permitted by statutory regulation or exceeds the permitted use, you will need to obtain permission directly from the copyright holder. To view a copy of this licence, visit http://creativecommons.org/licenses/by/4.0/. 


\section{Background}

Egypt has the highest hepatitis $\mathrm{C}$ virus (HCV) prevalence worldwide where about $24 \%$ of the people are estimated to carry HCV [1]. Viral hepatitis was estimated to be the 7th leading cause of mortality globally. About half of this mortality is attributed to hepatitis $\mathrm{C}$ virus (HCV) [2]. $\mathrm{HCC}$ is the most common primary liver cancer with over one million new cases worldwide annually. Globally, it is the third leading cause of cancer-related deaths [3]. Alpha fetoprotein (AFP) is still the most widely used tumor biomarker currently available for detection and clinical follow-up of patients with HCC with a sensitivity of 41$65 \%$ and a specificity of $80-94 \%$. Internationally, AFP cutoff level of $200 \mathrm{ng} / \mathrm{mL}$ is indicative of HCC [4]. Acute and chronic viral hepatitis as well as patients with cirrhosis caused by hepatitis $\mathrm{C}$ may be associated with slightly high AFP levels. However, this widely used marker does not yield satisfactory results in the early diagnosis of HCC limiting the universality of its application due to its low positive rate, false-positive results, and finally false-negative results [5]. As for the diagnosis of HCC, the European Association for the Study of the Liver (EASL) panel of experts and the recently updated American Association for the Study of Liver Diseases (AASLD) guidelines have proposed that imaging technique computed tomography and/or magnetic resonance imaging (CT or MRI) showing the HCC radiological hallmark, contrast uptake in the arterial phase, and washout in the venous/late phases could diagnose tumors of $1-2 \mathrm{~cm}$ in diameter or above [6]. IL-18 is an $18-\mathrm{kDa}$ cytokine, originally known as interferon- $\gamma$ (IFN- $\gamma)$-inducing factor. This cytokine is mainly produced by activated macrophages and Kupffer cells and can promote IFN- $\gamma$ production [7]. Also, it participates in chronic hepatic inflammation, leading to carcinogenesis. It was reported that the serum level of IL-18 is a useful biological marker of tumor invasiveness and an independent prognostic factor for survival among patients with HCC [8]. Furthermore, the serum level of IL-18 is increased in patients with HCV-related stage IV HCC compared with patients with earlier-stage HCC [9]. IL-18 polymorphism has been proposed as a possible prognostic factor for reduced survival in patients with HCC [10]. IL18 polymorphism has been clearly demonstrated that it contributes to tumor progression and metastasis. Although genetic predisposition is one of the factors critical for HCC progression, few studies have focused on IL18 single nucleotide polymorphisms (SNPs) in patients with HCC. Moreover, research on the combined effect of IL-18 SNPs and HCV infection on the risk and clinicopathologic development of HCC remains scanty [11].

\section{Objectives}

Thus, the aim of the present study was to analyze the interleukin-18 polymorphism as a diagnostic tumor marker for hepatocellular carcinoma in patients with hepatitis C-related cirrhosis.

\section{Methods \\ Study design}

The present study was a cross-sectional study.

\section{Settings}

The study was conducted at Mansoura Specialized Medical Hospital outpatient clinics without recruitment for 9 months of follow-up.

\section{Participants}

This study included 33 HCC complicating HCV-related cirrhosis patients (HCC group), 37 cirrhotic patients without HCC (cirrhosis group), and 20 healthy individuals who were included as a control (control group), and all of them were from Mansoura Specialized Medical Hospital outpatient clinics for 9 months. SNPs of the IL18 gene were genotyped by polymerase chain reaction (PCR) restriction fragment-length polymorphism assays.

\section{Variables}

The inclusion criteria were as follows:

- HCC complicating HCV-related cirrhosis patients and cirrhotic patients without HCC

- Both groups are naive

- Both gender (62.82 years mean age for the HCC group and 57.78 mean age for the cirrhosis group)

- All stages of Child-Pugh

The exclusion criteria were as follows:

- Patients with a history of cancers other than the liver

- Previous liver transplantation

- Patients co-infected with HIV or HBV

- Other organ failures (heart failure and renal failure)

\section{Data sources/measurement}

After taking a consent of the patients with ensuring the confidentiality of patients and control data, permission was taken from the head of the concerned department. All patients were subjected to history taking (name, age, sex of the patient, and smoking), previous exposure to $\mathrm{HCV}$ infection, history of liver disease, cirrhosis, history of medications and/toxin exposure, history of chronic diseases (DM, HTN, and other diseases), and family history of HCC. Physical examination includes a general examination for signs of liver cirrhosis (vital signs jaundice, general appearance, and spider nevi); local abdominal examination for the liver, spleen, and presence or absence of ascites; investigations-laboratory tests for 
Table 1 Relative risk factors for the current condition

\begin{tabular}{llll}
\hline Variable & Hazard ratio & $\mathbf{9 5 \% ~ C l}$ & $\boldsymbol{P}$ value \\
\hline Smoking & 1.44 & $1.02-2.11$ & 0.049 \\
DM & 1.11 & $0.96-1.29$ & 0.15 \\
Male gender & 3.96 & $2.65-5.93$ & $<0.001$ \\
Obesity & 1.03 & $0.66-1.63$ & 0.88 \\
\hline
\end{tabular}

This table shows the increase in the relative risk of both smoking and male gender in HCC patients ( $P=0.049$ and $P<0.001$, respectively)

$P$ value $<0.05$ is significant

$\mathrm{Cl}$ confidence interval

virology markers $\mathrm{HBsAg}, \mathrm{HCV}$ Ab (ELISA), and $\mathrm{HCV}$ $\mathrm{PCR}+\mathrm{ve}$ in all patients and biochemical tests for liver function tests [S. albumin, S. bilirubin, prothrombin time, INR ratio, ALT, AST], serum level of alpha fetoprotein, complete blood count, S. creatinine, and IL-18 polymorphism genotyped by polymerase chain reaction (PCR) restriction fragment-length polymorphism assays with its variants and alleles A, C, and G; and radiology, specially assessing liver (cirrhosis or HCC on top of cirrhosis): abdominal US, triphasic CT abdomen, and liver biopsy.

Bias

N/A

\section{Study size}

The study size is determined by the statistician.

\section{Quantitative variables}

N/A

Table 2 Comparison of laboratory findings in cirrhosis and HCC groups

\begin{tabular}{llll}
\hline Variables & $\begin{array}{l}\text { Cirrhosis group } \\
(\boldsymbol{N}=\mathbf{3 7})\end{array}$ & $\begin{array}{l}\text { HCC group } \\
(\boldsymbol{N}=\mathbf{3 3})\end{array}$ & $\begin{array}{l}\text { Test of } \\
\text { significance }\end{array}$ \\
\hline PCR $\left(\times 10^{5}\right)$ & $11.08 \pm 12.48$ & $4.76 \pm 2.89$ & $P=0.178$ \\
SGPT & $39.73 \pm 29.29$ & $110.85 \pm 69.11$ & $P=0.001^{*}$ \\
SGOT & $43.57 \pm 24.76$ & $133.61 \pm 140.42$ & $P<0.001^{*}$ \\
Albumin & $4.11 \pm 0.61$ & $2.85 \pm 0.72$ & $P<0.001^{*}$ \\
Total bilirubin & $1.06 \pm 0.67$ & $9.68 \pm 10.81$ & $P<0.001^{*}$ \\
Direct bilirubin & $0.36 \pm 0.33$ & $6.67 \pm 7.86$ & $P<0.001^{*}$ \\
INR & $1.19 \pm 0.32$ & $1.46 \pm 0.37$ & $P<0.001^{*}$ \\
Creatinine & $0.79 \pm 0.25$ & $1.61 \pm 1.49$ & $P<0.001^{*}$ \\
Platelets & $145.08 \pm 59.88$ & $122.64 \pm 66.63$ & $P=0.062$ \\
Hgb & $12.91 \pm 1.94$ & $11.41 \pm 1.88$ & $P=0.002^{*}$ \\
WBCs & $5.51 \pm 1.31$ & $9.67 \pm 9.56$ & $P=0.034^{*}$ \\
\hline
\end{tabular}

This table shows significantly higher SGPT, SGOT, total bilirubin, direct bilirubin, INR, creatinine $(P<0.001$ for all), and WBCs $(P<0.034)$ in the HCC group and significantly lower albumin and $\mathrm{Hgb}$ in the HCC group $(P<0.001$ and $P=0.002$, respectively)

*Statistically significant if $P<0.05$
Table 3 Comparison of the AFP levels among the studied groups

\begin{tabular}{llll}
\hline & Mean \pm SD & Test of sig. & \\
\hline Control group $(N=20)$ & $2.87 \pm 1.25$ & $\mathrm{KW}=36.485$ & \\
Cirrhosis group $(N=37)$ & $10.12 \pm 15.16$ & $P<0.001^{*}$ & $P=0.345$ \\
HCC group $(N=33)$ & $345.67 \pm 504.25$ & & $P 1<0.001^{*}$ \\
& & & $P 2<0.001^{*}$ \\
\hline
\end{tabular}

This table shows that AFP is highly significant in the HCC group than the cirrhosis and control groups $(P<0.001)$

$K W$ Kruskal-Wallis test, $P$ intergroup probability, $p 1$ probability in relation to the control group, $p 2$ probability in relation to the cirrhosis group

\section{Statistical methods}

The collected data were coded and fed into the SPSS system (Statistical Package for Social Sciences) ver. 22.

\section{Results}

Participants

This study included $33 \mathrm{HCC}$ complicating HCV-related cirrhosis patients (HCC group), 37 cirrhotic patients without HCC (cirrhosis group), and 20 healthy individuals who were included as a control (control group).

\section{Descriptive data, outcome data, and main results}

Descriptive data, outcome data, and main results are shown in Tables 1, 2, 3, 4, 5, 6 and 7 .

\section{Other analyses \\ $\mathrm{N} / \mathrm{A}$}

\section{Discussion}

\section{Key results}

Our study included $33 \mathrm{HCC}$ complicating HCV-related cirrhosis patients (HCC group), 37 cirrhotic patients without HCC (cirrhosis group), and 20 healthy individuals who were included as a control (control group). The HCC patients were $26(78.8 \%)$ males and 7 (21.2\%) females, and the cirrhotic patients were 14 males $(37.8 \%)$

Table 4 ROC curve of AFP in the total studied patient

\begin{tabular}{lll}
\hline & Cirrhotic & HCC \\
\hline AUC (95\% Cl) & $0.696(0.56-0.83)$ & $0.926(0.85-0.99)$ \\
Cutoff point & $\geq 3.45$ & $\geq 4.50$ \\
Sensitivity (\%) & 62.2 & 84.8 \\
Specificity (\%) & 75.0 & 85.0 \\
PPV (\%) & 82.1 & 90.3 \\
NPV (\%) & 51.7 & 77.3 \\
Accuracy (\%) & 66.7 & 84.9
\end{tabular}

This table shows that the sensitivity and specificity of AFP in HCC patients ( $84.8 \%$ and $85 \%$, respectively) and in the cirrhotic group (62.2\% and $75 \%$ respectively). The PPV and NPV in the HCC group are $90.3 \%$ and $77.3 \%$, respectively, and $82.1 \%$ and $51.7 \%$, respectively, in the cirrhotic group AUC area under the curve, PPV positive predictive value, NPV negative predictive value, $P$ probability 
Table 5 Comparison of different IL-18 genotypes in the studied groups

\begin{tabular}{|c|c|c|c|c|c|}
\hline & Group & & & $P$ value & \\
\hline & Control group $(N=20)$ & Cirrhosis group $(N=37)$ & HCC group $(N=33)$ & & $\begin{array}{l}\text { group } \\
\text { significance }\end{array}$ \\
\hline AA & $4(20 \%)$ & 11 (29.7\%) & 9 (27.3\%) & $P=0.727$ & $\begin{array}{l}\mathrm{p} 1=0.46 \\
\mathrm{p} 2=0.56 \\
\mathrm{p} 3=0.82\end{array}$ \\
\hline$A C$ & $12(60 \%)$ & 19 (51.4\%) & $18(54.5 \%)$ & $P=0.822$ & $\begin{array}{l}p 1=0.53 \\
p 2=0.69 \\
p 3=0.79\end{array}$ \\
\hline CC & $4(20 \%)$ & 7 (18.9\%) & $6(18.2 \%)$ & $P=0.972$ & $\begin{array}{l}\mathrm{p} 1=0.92 \\
\mathrm{p} 2=0.92 \\
\mathrm{p} 3=1.0\end{array}$ \\
\hline CC & $0(0.0)$ & $1(2.7)$ & $1(3.0)$ & $P=0.98$ & $\begin{array}{l}\mathrm{p} 1=1.0 \\
\mathrm{p} 2=1.0 \\
\mathrm{p} 3=1.0\end{array}$ \\
\hline GC & $1(5 \%)$ & $8(21.6 \%)$ & $8(24.2 \%)$ & $P=0.191$ & $\begin{array}{l}\mathrm{p} 1=0.10 \\
\mathrm{p} 2=0.07 \\
\mathrm{p} 3=0.79\end{array}$ \\
\hline GG & 19 (95\%) & $28(75.7 \%)$ & $24(72.7 \%)$ & $P=0.03^{*}$ & $\begin{array}{l}\mathrm{p} 1=0.07 \\
\mathrm{p} 2=0.04^{*} \\
\mathrm{p} 3=0.78\end{array}$ \\
\hline
\end{tabular}

This table shows that there is only a statistically significant difference in the GG genotype in the HCC group in comparison with the control group $(P=0.04)$

p1 comparison of the control and cirrhosis groups, $p 2$ comparison of control and HCC, $p 3$ comparison of cirrhosis and HCC

and 23 females $(62.2 \%)$ while the control group included $15(75 \%)$ males and 5 (25\%) females.

The current study is conducted aiming to analyze IL18 single nucleotide gene polymorphism and its value in predicting HCC among HCV-related cirrhotic patients by studying $33 \mathrm{HCC}$ patients with HCV-related cirrhosis, 37 cirrhotic patients without HCC, and 20 healthy individuals properly selected as a control.

Of interest, the presence of GG genotype is more in healthy control than in HCC patients $(P=0.04)$ (Table 5). A finding that could consider the presence of genotype GG of IL-18 as a good predictive marker against HCC development evidenced by lack of difference between the other genotypes (AA, AC, CC, and $\mathrm{GC}$ ) in the studied groups and each other or the control.

Of interest, Estfanous et al. [12] reported that IL-18 polymorphism GG genotype and $G$ allele were significantly associated with a lower risk of chronic $\mathrm{HCV}$ infection.

Furthermore, we find that $\mathrm{G}$ allele can be a protective factor against cirrhosis HCC development. This is not matching with Bouzgarrou et al. [13] who reported that IL-18 polymorphism $\mathrm{C}$ allele was associated with a higher risk of cirrhosis and HCC.

There were scanty studies of IL-18 single nucleotide gene polymorphism in $\mathrm{HCV}$ patients with or without cirrhosis. Previous studies of HCC in HBV patients confirmed abstinence of significant association of different genotypes of IL-18 in the studied patients.

Dai et al. [14] reported that GG genotype carriers may increase the risk of HCC in healthy populations and the risk of LC in chronic hepatitis B carriers while Zhang and colleagues [15] reported that the AA genotype and A allele frequencies of IL-18 SNP were positively correlated with HBV-related HCC.

Table 6 Comparison of different IL-18 genotypes alleles in the groups

\begin{tabular}{|c|c|c|c|c|}
\hline \multirow{2}{*}{$\begin{array}{l}\text { IL-18 } \\
\text { genotype } \\
\text { allele }\end{array}$} & \multicolumn{3}{|l|}{ Group } & \multirow{2}{*}{$\begin{array}{l}\text { Within- } \\
\text { group } \\
\text { significance }\end{array}$} \\
\hline & Control group $(N=40)$ & Cirrhosis group $(N=74)$ & HCC group $(N=66)$ & \\
\hline A & $20(50.0 \%)$ & $41(55.4)$ & $36(54.6)$ & \multirow{2}{*}{$\begin{array}{l}\mathrm{p} 1=0.58 \\
\mathrm{p} 2=0.65 \\
\mathrm{p} 3=0.92\end{array}$} \\
\hline C & $20(50.0 \%)$ & $33(44.6)$ & $30(45.4)$ & \\
\hline G & $39(97.5)$ & $64(54.6)$ & $56(84.8)$ & \multirow{2}{*}{$\begin{array}{l}\mathrm{p} 1<0.001^{*} \\
\mathrm{p} 2=0.03^{*} \\
\mathrm{p} 3=0.78\end{array}$} \\
\hline C & $1(2.5)$ & $10(45.4)$ & $10(15.2)$ & \\
\hline
\end{tabular}

This table shows that there is a statistically significant difference in the $\mathrm{G}$ allele in the cirrhosis and HCC groups in comparison with the control group (p1 < 0.001 and p2 $=0.03$, respectively), and others were less significant

p1 comparison of the control and cirrhosis groups, p2 comparison of control and HCC, p3 comparison of cirrhosis and HCC 
Table 7 Binary logistic regression for prediction of HCC in the studied groups

\begin{tabular}{llll}
\hline IL-18 genotype & B & P & OR $(\mathbf{9 5} \%$ Cl) \\
\hline CC & B1 20.97 & p1 1.0 & OR1 undefined \\
& B2 20.82 & p2 1.0 & OR2 undefined \\
& B3 0.15 & p3 0.92 & OR3 $1.17(0.07-19.7)$ \\
GC & B1 1.85 & p1 0.09 & OR1 $6.33(0.73-55.2)$ \\
& B2 1.69 & p2 0.13 & OR2 $5.43(0.63-47.02)$ \\
& B3 0.15 & p3 0.79 & OR3 $1.17(0.38-3.58)$
\end{tabular}

GG (R)

This table shows that control patients with GC genotype have a risk for developing HCC and cirrhosis by 6.33- and 5.43-folds, respectively, more than those with GG genotype while cirrhotic patients with $\mathrm{CC}$ and GC genotype have a risk for developing $\mathrm{HCC}$ by 1.17 -folds more than those with GG genotype

$B 1$ constant of regression equation of HCC versus control group, B2 constant of regression equation of cirrhosis versus the control group, $B 3$ constant of regression equation of cirrhosis versus the HCC group, $p /$ comparison of the control and HCC groups, $p 2$ comparison of control and cirrhosis, $p 3$ comparison of cirrhosis and HCC, OR odds ratio, $\mathrm{Cl}$ confidence interval, $R$ reference group

A previous study conducted by Bao and colleagues [16] proved that GC genotype and $\mathrm{C}$ allele significantly associated with decreased HCC risk.

In contrast to our results, Bakr et al. [17] proved that IL-18 polymorphism AA and GG genotypes were significantly related to a higher risk of developing HCC, and GC genotype and $C$ allele were significantly associated with a lower risk of developing $\mathrm{HCV}$-related cirrhotic patient.

Lau and colleagues [11] reported that the IL-18 polymorphism with $\mathrm{GC}+\mathrm{CC}$ genotypes and $\mathrm{G}$ allele could be factors that increase the risk of HCC compared with those carrying the wild-type GG.

The explanation for the disparity of results between us and other studies may be attributed to the variation in genetic background between different ethnicities, different environmental factors, exposure to different carcinogens in different populations, and to a somewhat smaller sample size of our study population.

Finally, analysis of IL-18 single nucleotide gene polymorphism could be a valuable marker for prediction of progress towards cirrhosis in chronic HCV patients and also to subsequent development of $\mathrm{HCC}$ in $\mathrm{HCV}$ cirrhotic patients proved by the results of both GG genotype and its $\mathrm{G}$ allele in our studied patients.

\section{Limitations}

Elastography was not done as it is very expensive for our patients. Also, the relatively small number of patients was due to the difficulty in acceptance by patients to be included in a research study in addition to the high expense of the kits.

\section{Interpretation}

Our results should be interpreted with caution because of several limitations. Firstly, though we recruited 90 samples in this study, the sample size of each group was relatively small which may restrict its detailed subgroup analysis by the clinical index. Secondly, considering we just controlled four factors (D.M., gender, smoking, and obesity), other factors including environmental background, treatment protocols, and living habits may cause some bias. Thirdly, all participants were all from Mansoura Specialized Medical Hospital outpatient clinics, Egypt, which may not stand for all the Egyptian population.

\section{Generalizability}

The fundamental experiments should be further conducted to validate our results and explore the possible mechanism.

\section{Conclusion}

Analysis of IL-18 single nucleotide gene polymorphism could be a valuable marker for prediction of progress towards cirrhosis in chronic $\mathrm{HCV}$ patients and also to subsequent development of $\mathrm{HCC}$ in $\mathrm{HCV}$ cirrhotic patients proved by the results of both GG genotype and its $\mathrm{G}$ allele; also, cirrhotic patients with CC and GC genotype have a risk for developing HCC by 1.17 -folds more than those with GG genotype.

\section{Abbreviations \\ HCV: Hepatitis C virus; HCC: Hepatocellular carcinoma; SNPs: Single nucleotide polymorphisms; AFP: Alpha fetoprotein; CT: Computed tomography; MRI: Magnetic resonance imaging; IFN- $\gamma$ : Interferon-gamma; HBsAg: Hepatitis B surface antigen; Ab: Antibody; ELISA: Enzyme-linked immunosorbent assay; PCR: Polymerase chain reaction; ALT: Alanine aminotransferase; AST: Aspartate transaminase; SPSS: Statistical Package for the Social Sciences; AUC: Area under the curve}

\section{Acknowledgements \\ Thanks to every person shared in this work and the soul of Dr. Ayman A. Eldesoky.}

\section{Authors' contributions}

The authors have read and approved the manuscript. AAGD: idea of the study and data collection. NAFA: manuscript review, design, editing, publishing, and final revision (CA). HEDZ: laboratory studies. AAAA: literature search, clinical follow-up, and statistics.

\section{Funding}

Not applicable.

\section{Availability of data and materials}

The datasets used and/or analyzed during the current study are available from the corresponding author on reasonable request.

\section{Ethics approval and consent to participate}

The study protocol was investigated and approved by the Medical Ethics Research Team, Faculty of Medicine, Mansoura University (code number MS/ 16.12.39).

Every case, after guaranteeing privacy, has given informed written consent. 


\section{Consent for publication}

Not applicable.

\section{Competing interests}

The authors declare that they have no competing interests.

\section{Author details}

IInternal Medicine Department Hepatology \& Gastroenterology Unit, Mansoura Specialized Medical Hospital, Mansoura University Faculty of Medicine, Mansoura, Egypt. ${ }^{2}$ Clincal Pathology Department, Mansoura University Faculty of Medicine, Mansoura, Egypt. ${ }^{3}$ Dekernes Hospital, Dakahlia, Egypt.

Received: 29 July 2020 Accepted: 26 October 2020

Published online: 05 November 2020

\section{References}

1. Omar A, Abou-Alfa GK, Khairt A et al (2013) Risk factors for developing hepatocellular carcinoma in Egypt. Chin Clin Oncol 2(4):43

2. Kouyoumjian SP, Chemaitelly H, Abu-Raddad LJ (2018) Characterizing hepatitis $C$ virus epidemiology in Egypt: systematic reviews, meta-analyses, and meta-regressions. Sci Rep 8(1):1661

3. Murata S, Mine T, Ueda T et al (2013) Transcatheter arterial chemoembolization based on hepatic hemodynamics for hepatocellular carcinoma. Sci World J 479805:1-8

4. Behne T, Copur MS (2012) Biomarkers for hepatocellular carcinoma. Int Hepatol 2012:859076

5. Zhao YJ, Qiang JU, Guan-Cheng LI (2013) Tumor markers for hepatocellular carcinoma. Mol Clin Oncol 1(4):593-598

6. Bruix J, Sherman M (2011) Management of hepatocellular carcinoma: an update. Hepatology 53:1020

7. Yue M, Wang JJ, Tang SD et al (2013) Association of interleukin-18 gene polymorphisms with the outcomes of hepatitis $C$ virus infection in high-risk Chinese Han population. Immunol Lett 154:54-60

8. Tangkijvanich P, Thong-Ngam D, Mahachai V et al (2007) Role of serum interleukin-18 as a prognostic factor in patients with hepatocellular carcinoma. World J Gastroenterol 13:4345-4349

9. Shiraki T, Takayama E, Magari H et al (2011) Altered cytokine levels and increased CD4+CD57+ T cells in the peripheral blood of hepatitis C virusrelated hepatocellular carcinoma patients. Oncol Rep 26:201-208

10. Chen TP, Lee HL, Huang YH et al (2016) Association of intercellular adhesion molecule-1 single nucleotide polymorphisms with hepatocellular carcinoma susceptibility and clinicopathologic development. Tumour Biol 37(2):20672074

11. Lau H-K, Hsieh M-J, Yang S-F et al (2016) Association between interleukin-18 polymorphisms and hepatocellular carcinoma occurrence and clinical progression. Int J Med Sci 13(7):556-561

12. Estfanous SZK, Ali SA, Seif SM, Soror SHA (2019) Inflammasome genes' polymorphisms in Egyptian chronic hepatitis C patients: influence on vulnerability to infection and response to treatment. Mediators Inflamm 2019:3273645

13. Bouzgarrou N, Hassen E, Schvoerer E et al (2008) Association of interleukin18 polymorphisms and plasma level with the outcome of chronic HCV infection. J Med Virol 80:607-614

14. Dai ZJ, Liu X-H, Wang M et al (2017) IL-18 polymorphisms contribute to hepatitis B virus-related cirrhosis and hepatocellular carcinoma susceptibility in Chinese population: a case-control study. Oncotarget 8(46):81350-81360

15. Zhang QX, Yao YQ, Li SL et al (2016) Association between interleukin-18 gene polymorphisms and hepatocellular carcinoma caused by hepatitis B virus. Zhonghua Gan Zang Bing Za Zhi 24(5):352-357

16. Bao J, Lu Y, Deng Y et al (2015) Association between IL-18 polymorphisms, serum levels and HBV-related hepatocellular carcinoma in a Chinese population: a retrospective case-control study. Cancer Cell Int 15:72

17. Bakr NM, Awad A, Moustafa E (2018) Association of genetic variants in the interleukin-18 gene promoter with risk of hepatocellular carcinoma and metastasis in patients with hepatitis C virus infection. IUBMB Life 70(2):165174

\section{Publisher's Note}

Springer Nature remains neutral with regard to jurisdictional claims in published maps and institutional affiliations.

\section{Submit your manuscript to a SpringerOpen ${ }^{\circ}$ journal and benefit from:}

- Convenient online submission

- Rigorous peer review

- Open access: articles freely available online

High visibility within the field

- Retaining the copyright to your article

Submit your next manuscript at $\boldsymbol{\nabla}$ springeropen.com 